\title{
Selection of screw characteristics and operational boundary conditions to facilitate post-flush urine and faeces separation within single household sanitation systems
}

\author{
E. Mercer, P. Cruddas L. Williams, A. Kolios, A. Parker, S. Tyrrel, E. Cartmell, M. Pidou, E.J. \\ McAdam* \\ Cranfield Water Science Institute, Vincent Building, Cranfield University, Bedfordshire, MK43 OAL, UK \\ *Corresponding author e-mail: e.mcadam@cranfield.ac.uk
}

\begin{abstract}
To ensure adequate access to sanitation in developing economies, off-grid single household sanitation has been proposed which obviates the need for significant infrastructure capital investment. Whilst treatment at this scale is most efficient when coupled to source separation (i.e. urine from faeces), existing source separation solutions have proved difficult to implement in this context. In this study, screw extrusion is therefore investigated to provide 'post-flush' source separation. Both screw characteristics and operational boundary conditions were evaluated. Preferential screw characteristics included tapering of the shaft and progressive pitch reduction, linked to a small extrusion aperture, the combination of which enhanced solids extrusion efficiency and promoted higher solids concentration in the extruded fraction. Whilst maximum extrusion efficiency was observed at high rotational speeds (over $400 \mathrm{rpm}$ ), this also promoted free water transport. Operating below $300 \mathrm{rpm}$ instead introduced selectivity for transport of faecal sludge over urine, enabling phase separation. Constraining the volumetric ratio of urine to faeces also enhanced the extrusion rate of faecal sludge by increasing feed viscosity sufficient to overcome backpressure imposed by unmasticated food particles that would otherwise restrict separation. Importantly, this study demonstrates the feasibility of screw extrusion for 'post flush' separation of urine and faeces which constitutes a significant advancement towards realising sanitation at a single household scale.
\end{abstract}

Keywords: screw, faeces, urine, separation, solids concentration, extrusion 


\section{Introduction}

The Millennium Development Goal (MDG) target 7D proposed by the United Nations (UN) aimed to halve the proportion of people without access to safe drinking water and basic sanitation by 2015 . Whilst this has been achieved for drinking water, the target has fallen short for sanitation. According to a progress report by WHO/UNICEF, ${ }^{1} 2.4$ billion people are without access to improved sanitation with 946 million people continuing to practice open defecation.

Pit latrines are the principal form of sanitation infrastructure available to urban populations of low income countries, offering improved sanitation at low costs. ${ }^{2}$ However, pit latrines only allow for long term in-situ storage of faecal sludge which often leads to local groundwater contamination. ${ }^{3}$ Faecal sludge accumulates at an average rate of $0.1 \mathrm{~L} \mathrm{~d}^{-1}$ capita ${ }^{-1,}$, with the average pit $\left(2.5 \mathrm{~m}^{3}\right)$ expected to take 3 years to fill, assuming no degradation. ${ }^{5}$ However, this estimated fill rate neglects the volume attributable to urine (around $1.5 \mathrm{~L} \mathrm{~d}^{-1}$ capita ${ }^{-1}$ ), in addition to external factors such as groundwater intrusion, which constrains operational time between pit empties. ${ }^{6,7,8}$ Maintenance issues such as pit collapse and termite damage have also been reported to reduce unlined pit lifespans up to a maximum of 13 months. ${ }^{9,10}$ In a survey conducted by Chowdhry and Koné, average household scale pit emptying fees ranged from $\$ 35$ household $^{-1}$ in India to $\$ 95$ household $^{-1}$ in Kenya. ${ }^{11}$ These indicative costs are between $12 \%$ and $125 \%$ of an individuals' average monthly salary which emphasises the economic sensitivity to overfilling. ${ }^{12}$

In seeking to improve economics for pit latrine emptying, Rogers et al. demonstrated the novel use of a screw 'elevator' for application to compacted sludge at the base of pit latrines which would reduce the mechanical cost of pit emptying. ${ }^{8}$ The authors noted that low viscosity sludge could only be extruded through increasing rotational speed. This finding is significant as it suggests that selectivity toward faecal solid phase over the liquid phase can be imparted which could help minimise pit latrine emptying. Source separation of urine from faecal sludge has been advocated to reduce emptying frequency through direct volume reduction. To date, source separation has been facilitated through application of toilets comprising two anatomically sited entry points in the toilet 
bowl to enable diversion of urine from faecal sludge. Further to providing volume reduction of the stored faecal sludge, source separation reduces the faecal contamination of the urine, which then simplifies downstream treatment of both solid and liquid phases. ${ }^{13,14,15}$ Source separation is therefore conceived as an enabler to the introduction of household scale sanitation systems, such as those being developed through the recent, 'Reinvent The Toilet Challenge', promoted by the Bill \& Melinda Gates Foundation, which would eliminate both pit emptying and faecal sludge transportation costs. ${ }^{16}$ This is significant as restricted access and mechanical difficulties with sludge type encourage manual handing and high transportation costs stimulates direct disposal of faecal sludge into the environment, introducing a significant health risk to the local community.$^{17,18}$

Source separation systems have seen much success in Europe with urine regarded as a nutrient resource and power source. ${ }^{19,15,20,21}$ However, source separating toilets are prone to misuse. To illustrate, several studies have shown only 50 to $80 \%$ urine recovery, ${ }^{22,23}$ indicating substantive urine carryover into the faecal compartment. In addition, $50 \%$ of the world's population practice wet anal hygiene ${ }^{16}$ which will inevitably increase the 'unbound' water fraction of the separated faecal sludge. High variability of the arising waste stream characteristics increases the complexity in terms of downstream technology selection and operation. In this paper, it is proposed that the inherent complexity associated with fluid separation in addition to variability in fluid composition can be resolved through use of a non-source separating toilet interface coupled with mechanical phase separation post 'flush'.

The screw auger has potential to be employed as the mechanical component for phase separation in post 'flush' systems. It comprises a series of helical flights mounted on a central shaft. Advancement of the faecal sludge through the screw is provided by rotation, and the frictional resistance created. ${ }^{24,25}$ Historically, screws were primarily used for lifting water, which required a pitch of between $30^{\circ}$ and $38^{\circ} .{ }^{26}$ However, screw conveyors, screw feeders, screw elevators and screw extruders have since been developed for transport of a broad range of high solids, high viscosity applications including plastics, food, powders, animal feed, cement and wastewater 
sludge. ${ }^{27-30}$ In the plastics and food industry, product consistency is controlled through adaptation of screw extrusion which features an aperture or 'nozzle' of constrained size coupled to a compression section which decreases free volume towards the aperture. ${ }^{31,32,33}$ Whilst the work of Rogers et al. on pit latrine sludge is particularly encouraging, to the best of our knowledge there has been no study of the application of screw technology to non-source separating toilets. Specifically, the faecal sludge within a short residence time toilet will comprise of fresh faeces which are known to be of complex rheology and will inevitably differ from pit latrine sludge which has been subject to substantive biodegradation due to long storage times. ${ }^{34,35}$ Furthermore, owing to the short residence times adopted, faecal identity may be retained which would indicate the necessity to provide separation of individual faeces which comprise high solids concentration (11 to $34 \%$ ), heterogeneous composition and large particle size (up to 0.2 to $0.25 \mathrm{~m}$ in length). ${ }^{2}$ Consequently, in this study, a screw extruder was developed to permit post-flush phase separation of urine and faeces. Specifically, the study will aim to: (i) identify appropriate screw characteristics that enable extrusion of fresh faecal sludge; (ii) establish boundary conditions that can provide for phase separation and a high product solids concentration; and (iii) to identify conditions that will enable consistent throughput despite the complex rheology.

\section{Materials and methods}

\subsection{Experimental setup}

The experimental unit (Figure 1) was designed to process the waste of a typical household of 10 users day ${ }^{-1}$, which on average constitutes $15 \mathrm{~L}$ of urine and $2.5 \mathrm{~kg}$ of faeces (wet wt.) according to the literature. ${ }^{2}$ The bowl was fabricated (Model Products, Bedford, UK) from transparent Perspex to allow for a clear visual representation of the faecal settling, faecal loading and screw operation. The bowl was conical in shape with a depth of $50 \mathrm{~cm}$ and an entrance diameter of $35 \mathrm{~cm}$ decreasing to 7 $\mathrm{cm}$ at the base to facilitate settling. The screws were rapid prototyped from acrylonitrile butadiene styrene (ABS). The screw was fixed to a $60^{\circ}$ incline which is above the angle ordinarily required to lift 
water (around $38^{\circ}$; Lakeside screw pumps, 2015), to aid phase separation. The area of the screw (choke area) exposed to the faecal sludge was $50 \mathrm{~cm}^{2}$. Urine and faeces was loaded into the bowl and a 10 minute lag time allowed prior to experimentation to ensure complete particle sedimentation (separation). This ensured that error due to solids settling rates was eliminated. The screw was controlled by a motor connected to a phase inverter which provided a rotational speed range of 20 to $800 \mathrm{rpm}$ (BFL series, Oriental motors, Basingstoke, UK). The extrusion aperture was restricted at $0.85 \mathrm{~cm}^{2}$ to promote the compression of particles for product consistency and was modelled on the nozzle of a classical screw extruder. ${ }^{36}$ The resultant faecal product exited the rig via the extrusion aperture and was collected for mass and solids analysis.

\section{Screw characteristics}

A reference screw was designed with a constant pitch of $4 \mathrm{~cm}$ and shaft diameter of $4 \mathrm{~cm}$. To establish the advantage of individual screw characteristics, six further screws were designed which permitted evaluation of each characteristic identified (Table 1, Figure 2). Shaft diameter was explored by screws 5 and 6 (ranging from $2 \mathrm{~cm}-4 \mathrm{~cm}$ ), pitch was investigated with screws 1 and 2 (ranging from $2 \mathrm{~cm}-4 \mathrm{~cm}$ ) examining both constant and tapered features. Screw 3 possessed an exaggerated shaft diameter and pitch frequency. To investigate whether the screw is able to assist in screw loading, screw 4 was designed with starter flights. These were vertical ridges of $0.5 \mathrm{~cm}$ depth along the first $7 \mathrm{~cm}$ of the screw to promote 'grabbing' or pulling of the faecal sludge into the feed section. The compression ratio was determined using $:^{33}$

Compression ratio $=\frac{h_{\text {in }}}{h_{\text {out }}}$ Eq. 1 where $h_{\text {in }}$ is the difference in length between the shaft passage diameter and the shaft diameter at the entrance and $h_{\text {out }}$ at the exit.

Total dry solids within the system was determined by taking $5 \mathrm{~g}$ sub-samples (wet wt.) from the initial feedstock and at the extrusion aperture at timed sampling intervals following initiation. 
Total dry solids were determined using the standard method of drying samples in an oven overnight at $105^{\circ} \mathrm{C}^{37}$ The ability of the screw rig to transport solids was based on solids recovery within the extruded portion using:

Total solids recovered $(\%)=\frac{\text { Extruded solids mass }(g)}{\text { Initial solids mass }(g)} \times 100$

Alongside the total extrusion, performance was also based on subsamples of the extruded output in terms of extrusion rate $\left(\mathrm{g} \mathrm{s}^{-1}\right)$ and solids concentration (\%). These were collected at four time intervals of 10 second duration.

\subsection{Preparation and collection of synthetic and real faeces}

The operating conditions of the screw rig were firstly investigated using synthetic faeces (Table 2) to allow for consistent conditions when examining individual boundary conditions. The recipe was developed by the Pollution Research Group from the University of Kwazulu Natal to broadly correspond to the rheological properties of real fresh faeces. ${ }^{38}$ The analogue was slightly modified to structure into faecal form. The effects of pre-treatment were examined by modelling the synthetic faeces into $10 \mathrm{~cm}$ particles (unaltered faeces), $1 \mathrm{~cm}$ chopped cubed or completely mixed. The trials were based on a $500 \mathrm{~g}$ starting faecal mass and $3 \mathrm{~L}$ urine volume which represents the waste of 2 toilet users per day.

The real faeces collection regime was approved through Cranfield University's Research Ethics System (CURES). Faecal collection was undertaken using consenting anonymous volunteers. Boxes containing a list of instructions, gloves, disposable sampling bowls, a waste bag and sample bag, were conveniently placed within the toilet area. The boxes were collected daily to reduce odour for volunteers and maintain the freshness of the faeces. Each individual faeces was weighed, classified on the Bristol Stool Scale, analysed for total dry solids and combined to reach $500 \mathrm{~g}$. Depending on the trial, they were directly placed into the bowl (unaltered), chopped on $1 \mathrm{~cm}$ by 1 $\mathrm{cm}$ graph paper for accuracy or mixed thoroughly within the bowl with $3 \mathrm{~L}$ of water. A 10 minute lag 
time allowed prior to experimentation to ensure complete particle sedimentation (separation). A 24 hour trial was also introduced to understand the effect of settling on throughput. Both synthetic and real faeces trials were performed in triplicate.

\section{Results and discussion}

\subsection{Comparison of screw characteristics}

Critical screw characteristics were compared at a fixed rotational speed of $100 \mathrm{rpm}$ with the synthetic mixed faeces that were homogenised within the receiving bowl. Each screw variant was compared to reference Screw 7, which comprised a set pitch and shaft diameter of $4 \mathrm{~cm}$ (Figure 2). Through doubling pitch frequency from Screw 7 to Screw 1, it was evidenced that the total mass extruded was significantly different $(p<0.05)$. Whilst the average total solids extruded through tapering the screw (Screw 2 compared to Screw 7) was noted to be improved, the values were not significantly different $(p>0.05)$ (Figure 3). Screw 3 which comprised a tapered delivery section, and progressively narrowing pitch and shaft diameter, identified to provide the greatest solids processing within the fixed time interval of $100 \mathrm{~s}$ (Figure 3). It is therefore asserted that extrusion of faecal sludge is governed by three screw characteristics: (i) an increased number of flights, which will increase carrying capacity and introduce a commensurate reduction in pitch; (ii) a tapered pitch, providing progressive reduction in carrying capacity between flights toward the extrusion aperture; and (iii) a progressive tapering of shaft diameter toward the extrusion aperture, which provides a further reduction in carrying capacity between flights. The characteristics provided by Screw 3 (Figure 3) are analogous to screw extruder design where the compression section embedded in the shaft diameter increases with the direction of flow, which introduces pressure behind the aperture to drive fluid separation. ${ }^{31}$ Similar dimensional characteristics have been successful in screw systems used for municipal sewage sludge thickening. ${ }^{39}$

In addition to providing the highest specific volumetric throughput, the preferred screw achieved a higher solids concentration in the extruded product, of $14.2 \%$ compared to a maximum 
of only $10.4 \%$ achieved with the alternate screw designs tested under identical boundary conditions (Figure 4). This can be accounted for by the higher compression ratio employed in this study (3:1 compared to 1.5:1 which was the next highest compression ratio) which reduces the overall channel volume and increases the driving pressure. The comparable screw design is featured within commercial screw press design which has been demonstrated to reduce sewage sludge volume by up to $90 \% .{ }^{40}$

\subsection{The importance of faecal sludge pre-treatment on faecal solids extrusion efficiency}

Faecal sludge pre-treatment was assessed to ascertain whether changes to particle size were necessary to enhance extrusion efficiency of fresh faecal sludge (Figure 5, Table 3). Visual inspection of the screw feed zone evidenced that without pre-treatment, the synthetic faeces maintained their particle identity and their transition from the sedimentation tank into the screw feed zone was constrained by the choke length $(7 \mathrm{~cm})$. Partial pretreatment (chopping into small sections) and full pretreatment (thorough blending) of faecal sludge evidenced the capability to enhance solids extrusion efficiency (Figure 5). Analysis of faecal sludge distribution through Screw 3 indicated that whilst only around $30 \%$ of the faecal sludge was extruded within the fixed time period, a further 24 $\%$ was loaded within the screw (Figure 5). Therefore, in steady state operation (after initial priming), the solids recovery would be substantially higher (in this case $54 \%$ ), indicating the potential for further recovery through increasing the number of revolutions. It is asserted that whilst pretreatment is evidenced to be advantageous, increasing choke length to provide increased contact between the screw feed section and faecal sludge maybe sufficient to promote uptake of coarse faecal diameter particles without pretreatment, which is substantiated by Rogers et al. who also concluded that extending choke length can provide some increase in flow for high viscosity mixtures. ${ }^{8}$ 


\subsection{The effect of rotational speed on faecal solids extrusion efficiency and phase separation}

Screw 3 was adopted for further assessment of rotational speed, due to the enhanced solids recovery demonstrated. Whilst rotational speed was varied, solids extrusion efficiency was based on a fixed number of revolutions to provide comparison (Figure 6). An increase in rotational speed from 40 to $400 \mathrm{rpm}$ markedly increased the total dry solids extruded. An increased rotational speed is associated with an increase in shear, feed pressure and vortex motion which promotes the advancement of the faecal sludge through the screw. ${ }^{36,41,42}$ Maximum solids extrusion within the fixed processing interval (200 rotations) was evidenced at $400 \mathrm{rpm}$. Roberts described conveyance of non-cohesive granular material to be a function of the fill and vortex efficiency with material back slippage limiting conveyance; the vortex efficiency being induced by screw rotational speed. ${ }^{29,42,43}$ In this study, back slippage was not observed following cessation of screw operation. This is analogous to observations made with concentrated bentonite slurry, which exhibited a high friction coefficient and suggests that solids extrusion efficiency is constrained by the rate of faecal sludge entering the screw rather than back slippage. ${ }^{8}$

Increasing rotational speed above $400 \mathrm{rpm}$ did not increase solids extrusion efficiency. To illustrate, the solids recovery for $400 \mathrm{rpm}$ was $45 \% \pm 3 \%$ compared to $43 \% \pm 4 \%$ at $600 \mathrm{rpm}$. It is asserted that conveyance above $400 \mathrm{rpm}$ was constrained by the feed rate and potential conveying capacity of the screw. ${ }^{42}$ Santos and Chhabra suggested that when the screw feeds more material than the aperture can process, which in this study is induced by increasing rotational speed, then the back pressure will overcome the pressure required for extrusion. ${ }^{32}$ Therefore, the plateau in solids extrusion efficiency noted in this study (Figure 6) could also result from the extrusion aperture selected which was $0.85 \mathrm{~cm}^{2}$, and can impose a resistance to flow through back pressure. Free water uptake by screw extrusion was subsequently assessed and it was determined that provided rotational speed is maintained below $300 \mathrm{rpm}$, negligible free water transport will occur (Figure 7). For comparison, in previous trials using synthetic faecal sludge, solids extrusion was possible at 
rotational speeds of less than $100 \mathrm{rpm}$ (Figure 6). The difference in transport between the two fluid phases can be explained by the lower friction coefficient of water and the screw angle adopted, which is around $20^{\circ}$ steeper than conventional screws used to lift water. ${ }^{26}$ The capability for fluid separation has been similarly evidenced in a model $5 \%$ bentonite solution, where a minimum rotational speed of $300 \mathrm{rpm}$ was identified to enable free water transport. ${ }^{8}$

\subsection{Impact of faeces to urine volumetric ratio on solids extrusion efficiency}

The impact of faecal sludge to urine volumetric ratio on solids extrusion efficiency was evaluated at a rotational speed of $100 \mathrm{rpm}$ to limit free water ingress during faecal sludge extrusion. Analysis of faecal sludge distribution evidenced that for water volumes of 0.5 and $1 \mathrm{I}$, all of the faecal sludge present in the bowl has been extruded within the prescribed timeframe (100 s). Solids extrusion efficiency was observed to decline following an increase in the water fraction (Figure 8). For example, when the water fraction was doubled from $0.5 \mathrm{I}$ to $1 \mathrm{I}$ and subsequently increased to $3 \mathrm{I}$, solids extrusion rate declined from $833 \mathrm{~g} \mathrm{~min}^{-1}$ to 678 and $438 \mathrm{~g} \mathrm{~min}^{-1}$ respectively, illustrating that a six times dilution of average faecal solids concentration, approximately halved solids extrusion rate. It is therefore asserted that the reduction in solids extrusion rate at higher water volume is not directly associated with dilution but rather can be ascribed to a reduction in faecal sludge viscosity which reduces the friction coefficient and can promote back slippage. ${ }^{29,42,43}$

\subsection{Application of screw extrusion to real, fresh human faeces}

In contrast to the synthetic faeces trials, the impact of pretreatment upon the solids extrusion efficiency of fresh human faeces was less evident, and a greater mass of fresh human faeces was processed without pretreatment (Figure 9). However, this experimental evidence does not provide definitive resolution as to the importance of pretreatment for maximising solids extrusion efficiency, as each of the comparative trials (unaltered, chopped, mixed) which were conducted with 3 I of water were cut short due to blockages caused by large undigested food particles (Figure 10) which 
concentrated behind the extrusion aperture. The resident solids appeared reasonably dewatered, and yielded a total dry solids concentration of 20 to $24 \%$, equivalent to that of a healthy human stool. ${ }^{2}$ Qualitative analysis identified the presence of unmasticated whole foods such as corn (around $0.5 \mathrm{~cm}^{2}$ ), tomato seeds, fibrous tomato skins (around $1 \mathrm{~cm}^{2}$ ) and roughage concentrated behind the aperture. Screw 3 was compared with Screw 1 to identify whether the pitch and shaft characteristics of Screw 3, which ostensibly promote consolidation, were responsible for the arising blockages (Figures $10 \mathrm{a}$ and b). The comparison evidenced blockage of both screws behind the extrusion aperture. Santos and Chhabra proposed that the aperture diameter should be eight times larger than the particulate material to avoid clogging. ${ }^{32}$ Use of a larger diameter extrusion aperture may then be beneficial to obviate blockages; although this may reduce compression behaviour and so reduce the arising faecal solids concentration.

Importantly, when a lower urine to faeces ratio was employed (1:1), which increases the averaged solids concentration in the post-flush sedimentation tank, complete extrusion from the tank was possible without introducing blockage of the extrusion aperture (Figure 12). This can be accounted for by the higher fluid viscosity which sufficiently increased feed pressure to compensate for the backpressure introduced at the extrusion aperture by unmasticated foods. Whilst the initial faecal solids concentration ranged between 12 and $53 \%$ (before the addition of water) across all of the human faeces tests undertaken, the solids concentration of the extruded fraction varied by only $\pm 2 \%$, which indicates that the selected screw characteristics can provide some consistency. The impact of faecal sludge storage time was subsequently studied and whilst sedimentation of the faecal solids was observed to occur in around ten minutes, an averaged solids extrusion rate of $794 \mathrm{~g}$ $\min ^{-1}$ was observed for faecal sludge stored for 24 hours compared to only $276 \mathrm{~g} \mathrm{~min}^{-1}$ for a storage time of ten minutes. Furthermore, the average solids recovery after 24 hours was $23.6 \% \pm 4.4 \%$ compared to $11.9 \% \pm 4.2 \%$ after 10 minutes settling time. It is therefore proposed that storage encourages bonding of the stored sludge, increasing fluid viscosity, and hence the efficiency of extrusion. 


\section{Knowledge transfer to post flush source separation of urine and faeces}

In this study, preferential screw characteristics and operational boundary conditions have been identified that enable post-flush faecal sludge transport and phase separation. In the context of applying screw extrusion for post-flush phase separation of urine and faeces in single household scale toilets, several recommendations can be made. A screw comprised of: a continually diminishing pitch and tapered shaft diameter appears preferential for faecal sludge extrusion. A rotational speed of $400 \mathrm{rpm}$ provided maximum solids extrusion efficiency. However, at this rotational speed, urine can be simultaneously transported. Therefore whilst less efficient, it is recommended that an operating rotational speed below $300 \mathrm{rpm}$ is specified. A plateau in solids extrusion efficiency was achieved for rotational speeds exceeding $400 \mathrm{rpm}$, which it is suggested could have been constrained by feed rate. Therefore increasing the applied choke length to increase feed flow rate may offset the lower solids extrusion efficiency experienced at rotational speeds of $300 \mathrm{rpm}$ or below.

For synthetic faeces, pretreatment was a prerequisite to enabling sufficient engagement between faecal sludge and the screw feed section to initiate extrusion, as the applied choke constrained contact. Whilst this was not specifically evidenced when applied to fresh human faeces due to blockages, we suggest that an analogous problem is presented with human faeces that sustain their characteristic shape following sedimentation, and propose that extension of the choke length may be sufficient to enable the necessary engagement for extrusion without pretreatment of the faecal sludge. However, adaptation of the preliminary flights as a pretreatment, similar to those incorporated in progressive cavity pumps for primary sludge pumping, ${ }^{44}$ could also advantage extrusion efficiency through enabling preliminary particle size reduction of coarse unmasticated food particles prior to extrusion. This would also enhance resilience to foreign materials such as toilet paper, which should be considered for certain user groups. 
Blockages were also diminished during extrusion through limiting the water to faeces ratio to $1: 1$. Following the introduction of faeces and urine into the toilet, faecal particles quickly settle, creating a solid-liquid interface. A water to faeces ratio near 1:1 can then be practically achieved by: (i) operating the screw in batch thus allowing faecal sludge volume to develop; and (ii) incorporating a weir structure to permit physical separation of the liquid phase. ${ }^{45}$ The screw characteristics employed are similar to those used for screw extruders in the plastics industry to promote thickening and product consistency. ${ }^{46}$ Reasonably consistent solids concentration (in the extruded sludge) was demonstrated in each of the human faeces trials undertaken, which was mediated by the extrusion aperture. An increase of the extrusion aperture area may be necessary to limit blockages but the impact on consistency of the extruded fraction (solids concentration) should be closely examined. Real human faeces trials were operated at $400 \mathrm{rpm}$ and thus were subject to some free water inclusion which constrained the final product solids concentration to between 12 and 15 $\%$. However, the dewatered material recovered from within the metering screw section was around $25 \%$, which is the effective solids concentration of a healthy human stool. This demonstrates that with the optimisation of the relationship between rotational speed, screw pitch, aperture selection and feedstock viscosity, the output solids concentration can be further increased, improving downstream drying process efficiency. As such, effective post-flush fluid separation (i.e. urine and faeces) is possible, sufficient to facilitate practicable sanitation solutions at a household scale.

\section{Conclusions}

In this study, the feasibility of screw extrusion for post-flush phase separation of urine and faeces has been demonstrated. Post-flush source separation can therefore be considered a platform technology on which treatment capacity can be integrated which constitutes a significant advancement towards realising sanitation at a single household scale. Preferential screw characteristics and operational boundary conditions have been identified to facilitate post flush urine and faeces separation which include: 
- Screw characteristics identified included tapering of the shaft and progressive pitch reduction, linked to a small extrusion aperture, the combination of which provided around a $200 \%$ increase in solids extrusion

- Operation below $400 \mathrm{rpm}$ which is below the maximum extrusion efficiency but can facilitate phase separation.

- $\quad$ For synthetic faeces, it was observed that application of pretreatment to reduce faecal particle size increased mobility of faecal sludge into screw feed section. Further confirmation as to whether an expansion in choke length is sufficient to eliminate the need for particle size reduction.

Several other areas of investigation are also warranted:

- $\quad$ Further analysis of the feed section to enhance breakage/ shredding of coarse food particle. This would also help transition faecal sludge from the sedimentation tank into the screw feed section through breakage of coarse faeces.

- Evaluation of the trade-off between an increase in extrusion aperture dimensioning to obviate risk of blockage from unmasticated food particles versus the reduction in back pressure that an increased aperture dimension will provide, potentially reducing the extruded solids concentration.

- Operation during steady state versus start-up. This study has investigated screw loading and operation through start up performance. Steady state operation would demonstrate higher solids recovery with an already primed screw with continuous operation promoting particle compression against the extrusion aperture. Once primed, the screw could potentially operate at lower rotational speeds.

\section{Acknowledgements}


This publication is based on research funded by the Bill \& Melinda Gates Foundation. The findings and conclusions contained within are those of the authors and do not necessarily reflect positions or policies of the funders. Enquiries for access to the data referred to in this article should be directed to: researchdata@cranfield.ac.uk

\section{References}

1. WHO/UNICEF,http://www.unicef.org/publications/files/Progress_on_Sanitation_and_Drinking_ Water_2015_Update_.pdf (Accessed January 2015).

2. C. Rose, A. Parker, B. Jefferson, B and E. Cartmell, Crit. Rev. Env. Sci. Technol., 2015, 45, 18271879.

3. J. Grahamand M. Polizzotto, Environ. Health Perspect., 2013, 121, 521-530.

4. K. Foxon, C. Buckley, C. Brouckaert and B. Bakare, What Happens When the Pit is Full ? Developments in on-site Faecal Sludge Management (FSM), 2011, Water Research Commission, Durban.

5. D. Still, and K. Foxon, Tackling the Challenges of Full Pit Latrines, Volume 3: The development of pit emptying technologies. Water Research Commission, Gezina, 2012.

6. J. Pickford, Low-cost sanitation: a survey of practical experience, ITDG Publishing, London, 1995.

7. D. Still, presented in part at Biennial Conference of the Water Institute of Southern Africa, Durban, May, 2002.

8. T. Rogers, D. F. de los Reyes III, W. Beckwith, W and R. Borden, R, J Water Sanit. Hyg. De., 2014, 4, 72-80.

9. B. Cole, J. Pinfold, G. Ho and M. Anda, J. Water, Sanit. Hyg. Dev., 2012, 02.4, 266-278.

10. R. Chidya, R. Holm, M. Tembo, B. Cole, P. Workneh and J. Kanyama, Environ. Sci.: Water Res. Technol., 2016, DOI: 10.1039/c5ew00246j. 
11. S. Chowdhry and D. Kone, Business analysis of fecal sludge management: Emptying and transportation services in Africa and Asia, The Bill and Melinda Gates Foundation, Seattle, 2012.

12. World Bank, http://data.worldbank.org/products/wdi (Accessed May, 2016).

13. H. Kirchmann and S. Pettersson, Fert. Res., 1994, 40, 149-154.

14. T. Larsen and W. Gujer, Water Sci. Technol., 1996, 34, 87-94.

15. M. Maurer, W. Pronk, and T. Larsen, Water res., 2006, 40, 3151-66.

16. R. Otterpohl, U. Braun, U. and M. Oldenburg, presented in part at the $5^{\text {th }}$ Specialised Conference on Small Water and Wastewater Treatment Systems, Istanbul, September, 2002.

17. M. Templeton, Environ. Sci.: Water Res. Technol., 2015, 1, 17-21.

18. A. Ingallinella, G. Sanguinetti, T. Koottatep, A. Montanger, M. Stauss, B. Jimenez, L. Spinosa, H. Odegaard and D. Lee, Water Sci. Technol., 2002, 46, 285-94.

19. J. Lienert and T. Larsen, Environ. Sci. Technol., 2010, 44, 556-566.

20. E.Tilley, Environ. Sci.: Water Res. Technol., 2016, 2, 320-335, DOI: 10.1039/C5EW00237K.

21. I. Ieropoulos, A. Stinchcombe, I. Gajda, S. Forbes, I. Merino-Jimenez, G. Pasternak, D. SanchezHerranz and J. Greenman, Environ. Sci.: Water Res. Technol., 2016, 2, 336-343.

22. H. Jönsson, T. Stenstrom, J. Svensson, J and A. Sundin, Water Sci. Technol., 1997, 35, 145-152.

23. B. Vinnerås, J. Biosci, 2001, 5, 29-50.

24. P. McGuire, Conveyors: Application, Selection and Integration, CRC Press, Florida, 2009.

25. B. Bolat, and M. Boğoçlu, J. trends dev. mach. assoc. technol., 2012, 16, 207-210.

26. Lakeside Screw Pumps, http://www.lakeside-equipment.com/bulletins/bul_217.pdf (Accessed September , 2015).

27. D. McGlinchey, Bulk solids handling: equipment selection and operation, Wiley-Blackwell, Oxford, 2008.

28. A. Srivastava, C. Goering, R. Rohrbach and D. Buckmaster, Engineering Principles of Agricultural Machines, ASABE, St. Joseph, MI, 1993. 
29. A. Roberts, presented in part at BELTCON, 11, International Materials Handling Conference, 2001.

30. Y. Yu, PhD thesis, University of Wollongong, 1997.

31. Y. Béreaux, J. Charmeau, J and M. Moguedet, J. Mater. Process. Technol., 2009, 209, 611-618.

32. E. Santos, and S. Chhabra, An Analysis of Archimedes Screw Design Parameters and their Influence on Dispensing Quality for Electronics Assembly Applications. State University of New York, 2006.

33. T. Womer, presented in Annual Technical Conference of the Society of Plastics Engineers Inc., Orlando, May, 2000.

34. S. Woolley, C. Buckley, J. Pocock and G. Foutch, J Water Sanit. Hyg. De, 2014, 4, 484-489.

35. C. Buckley, K. Foxon, C. Brouckaert, N. Rodda, C. Nwaneri, E. Balboni, Scientific Support for the Design and Operation of Ventilated Improved Pit Latrines (VIPS) and the Efficacy of Pit Latrine Additives, Water Research Commission, South Africa, 2008.

36. R. Janes and P. Winch, IMA J. Manag. Math., 1993 , 5, 399-415.

37. AWWA, Standard Methods for the Examination of Water and Wastewater 21st ed, American Public Health Association, Washington, D.C, 2005.

38. Pollution Research Group, presented in the Reinvent the Toilet Fair, India, May, 2014.

39. Mitsubishi Kakoki Kaisha, Ltd, http://www.kakoki.co.jp/english/products/e-019/index.html. (Accessed May, 2015).

40. Huber, http://www.huber.co.uk/products/sludge-treatment/sludge-dewatering/huber-screwpress-q-pressr.html (Accessed January 2016).

41. J. Xu and G. Duffy, Appita J., 2001, 54, 369-375.

42. A. Roberts, Powder Technol., 1999, 104, 56-67.

43. A. Roberts, Proceedings of the Institution of Mechanical Engineers, 1964, 178, 293-310.

44. M. Fahlgren, 2012. Handbook of sludge pumping, Xylem Water Solutions AB, Sundbyberg, Sweden. 
45. P.H. Cruddas, E.J. McAdam, A. Kolios, A. Parker, L. Williams, B. Martin, C.A. Buckley, S. Tyrrel, 2015. Biosolids Management Within the Nano Membrane Toilet - Separation, Thickening and Dewatering. WEF/IWA Residuals and Biosolids Conference, Washington DC, US, 7-10 June.

46. D. Rosato, Extruding plastics: a practical processing handbook, Springer Science and Business Media, 2013.

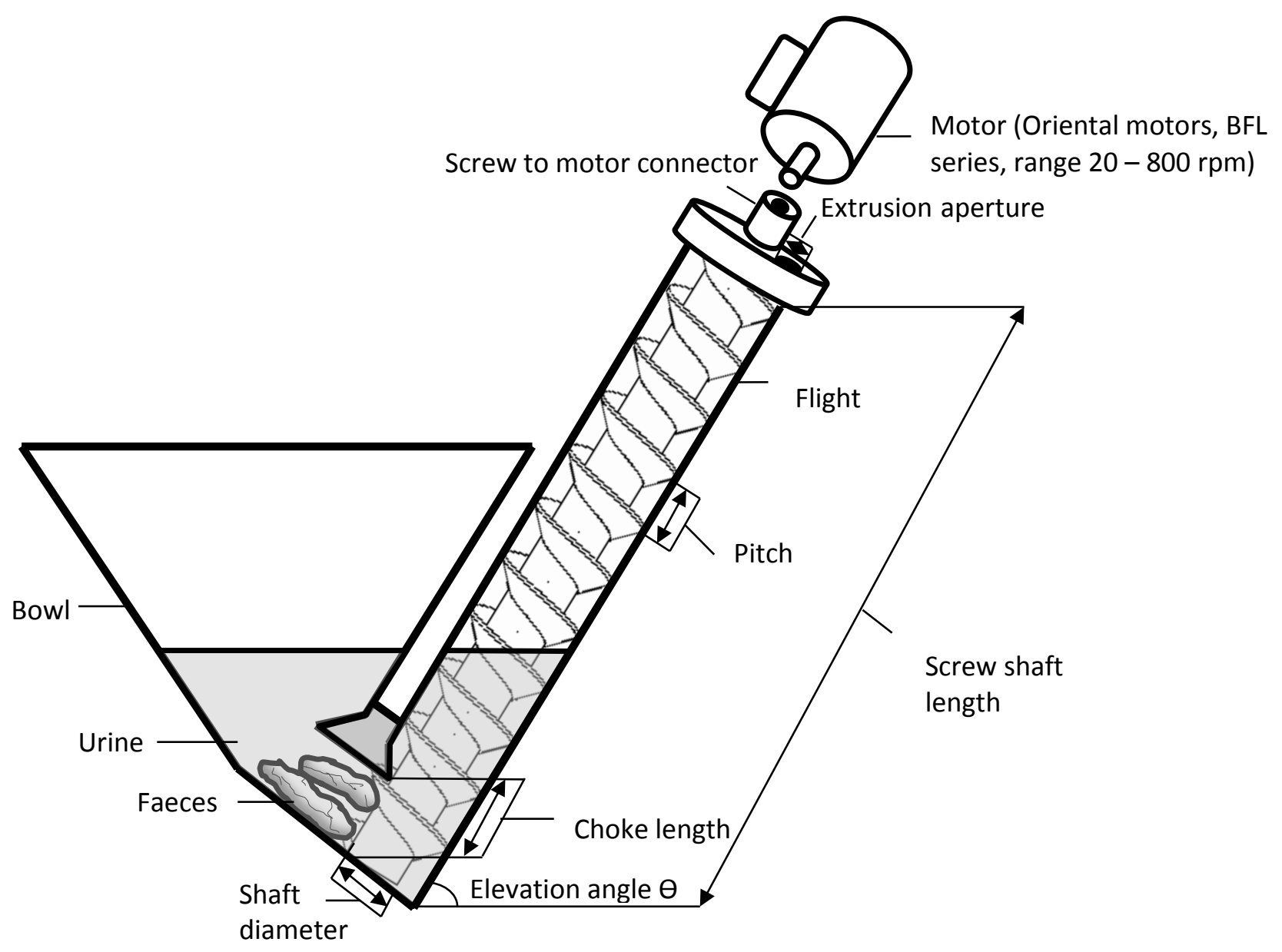

Figure 1. Experimental setup of the screw conveyor rig. 


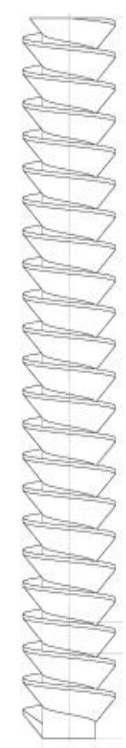

1

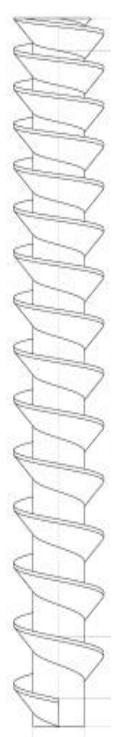

2

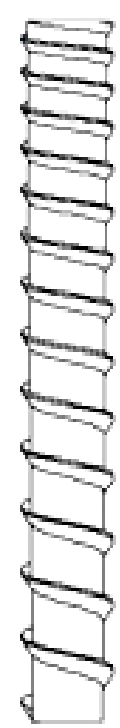

3

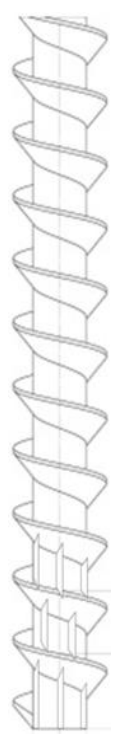

4

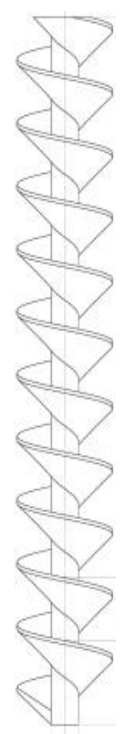

5
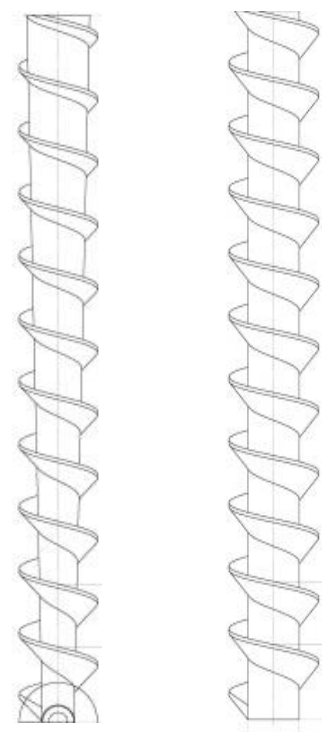

6

Figure 2. Schematics of screws 1-7.

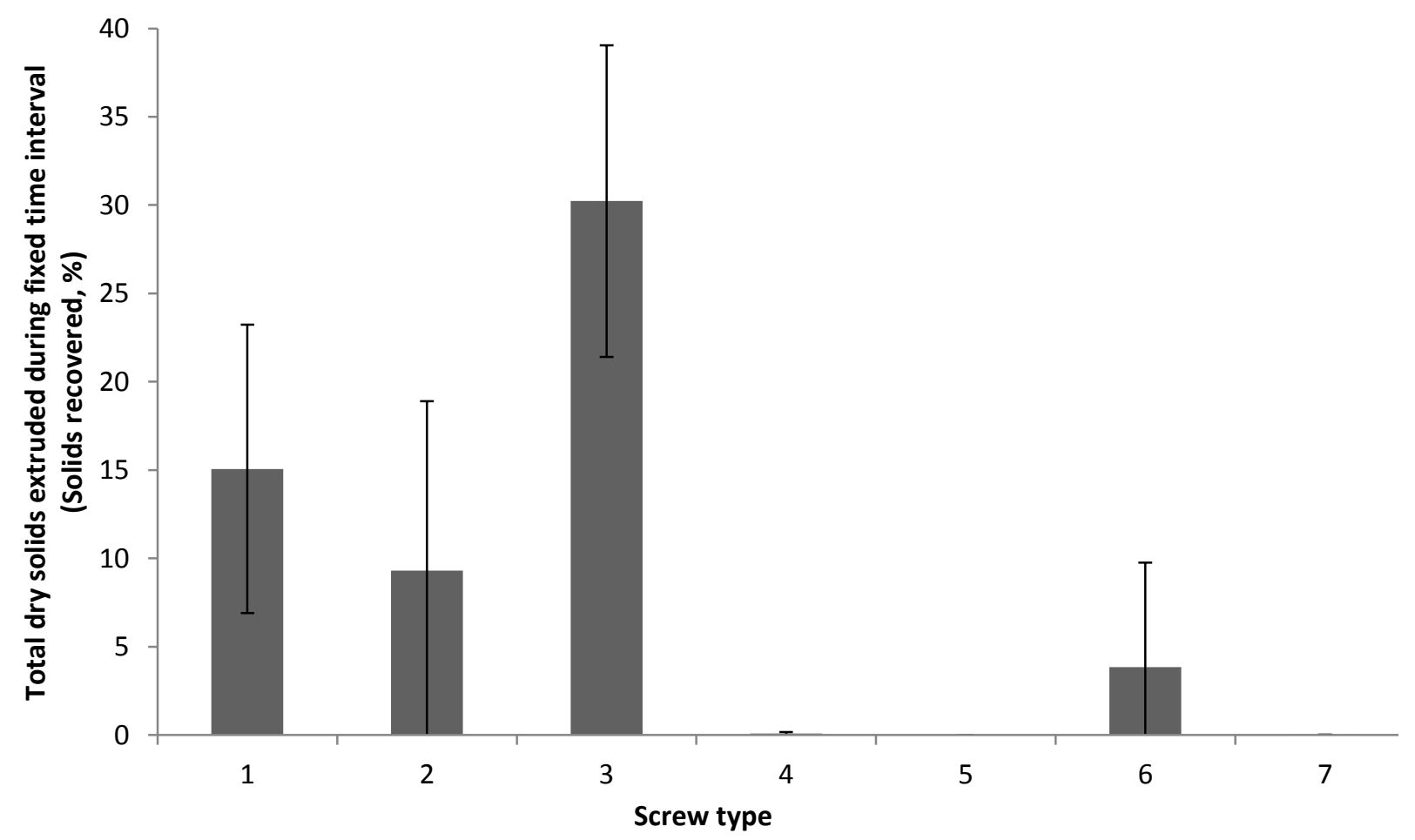

Figure 3. Comparison of screw types by the solids extruded from the initial loading (\%) within a prescribed time interval (Mixed form; 100 rpm; 100 seconds; 3 L water; 500 g synthetic faeces at 60 $\%$ solids content). 


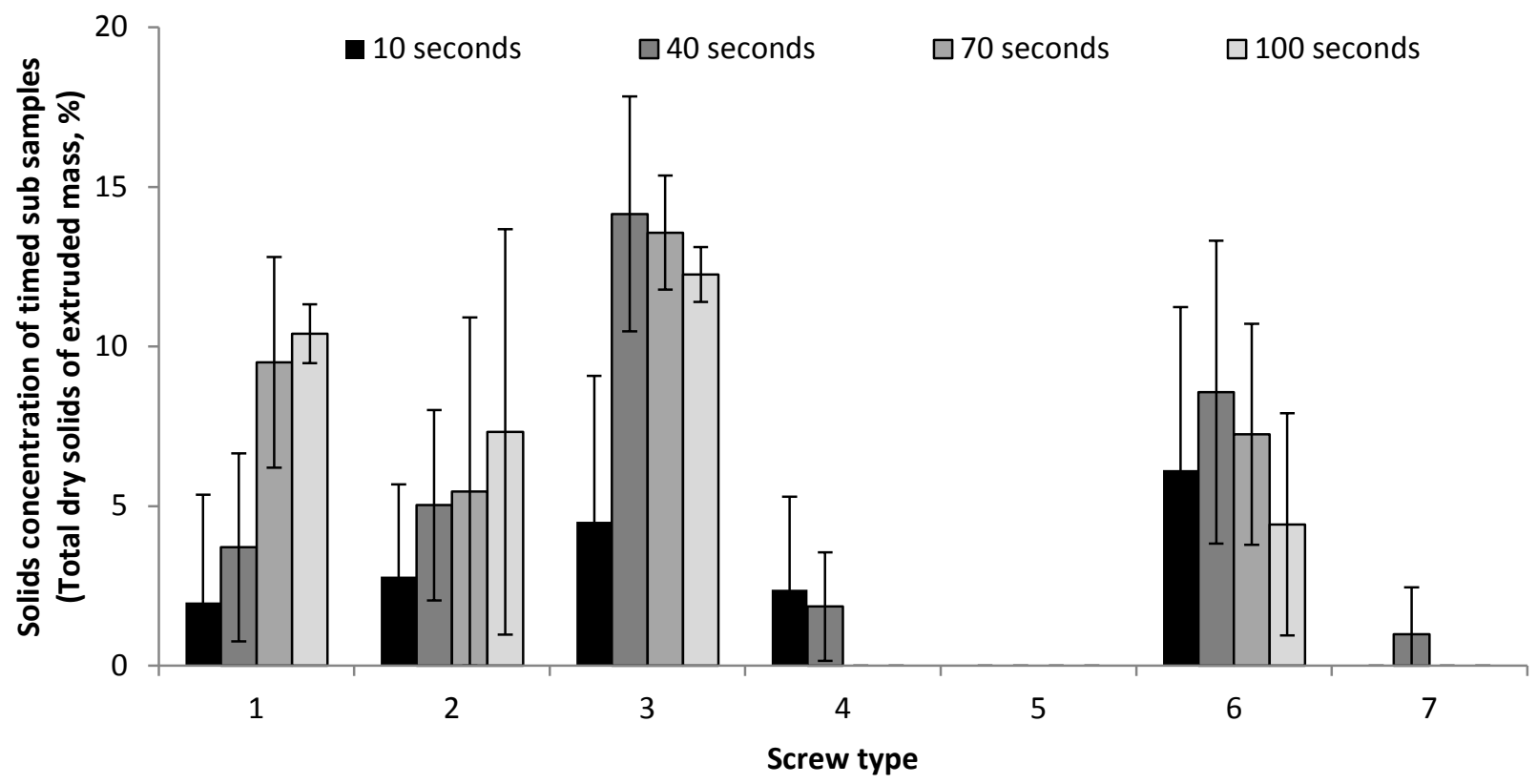

Figure 4. Solids concentration (\%) of output subsamples taken in 30 second intervals for a 10 second duration (Mixed form; 100 rpm; $3 \mathrm{~L}$ water; $500 \mathrm{~g}$ synthetic faeces at $60 \%$ solids content).

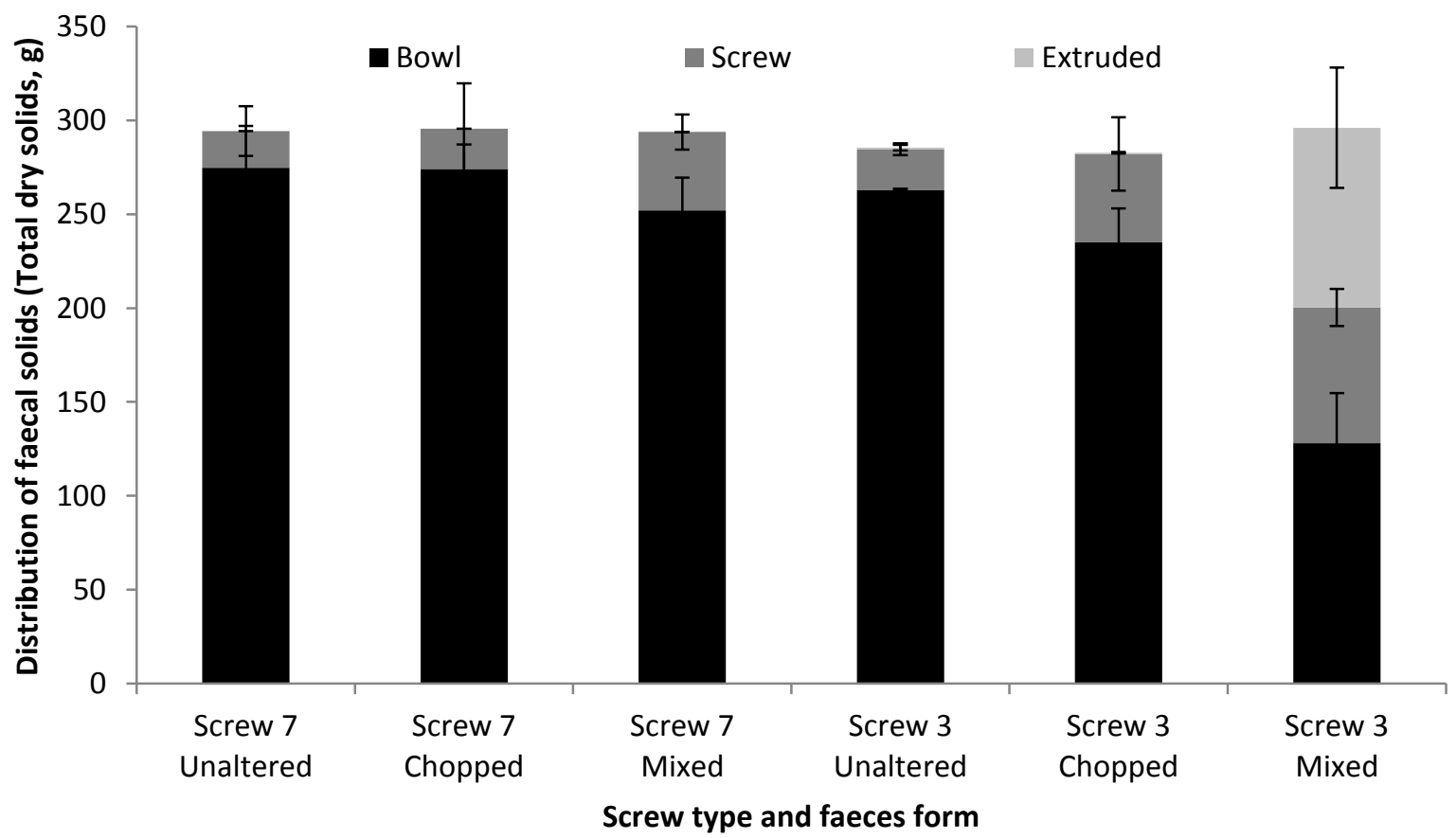

Figure 5. Distribution of total dry solids (g) by compartment for Screw 7 (reference) and Screw 3 following assessment at $100 \mathrm{rpm}$ for a fixed time interval of $100 \mathrm{~s}$ (100 rpm; 100 seconds; $3 \mathrm{~L}$ water; $500 \mathrm{~g}$ synthetic faeces at $60 \%$ solids content). 


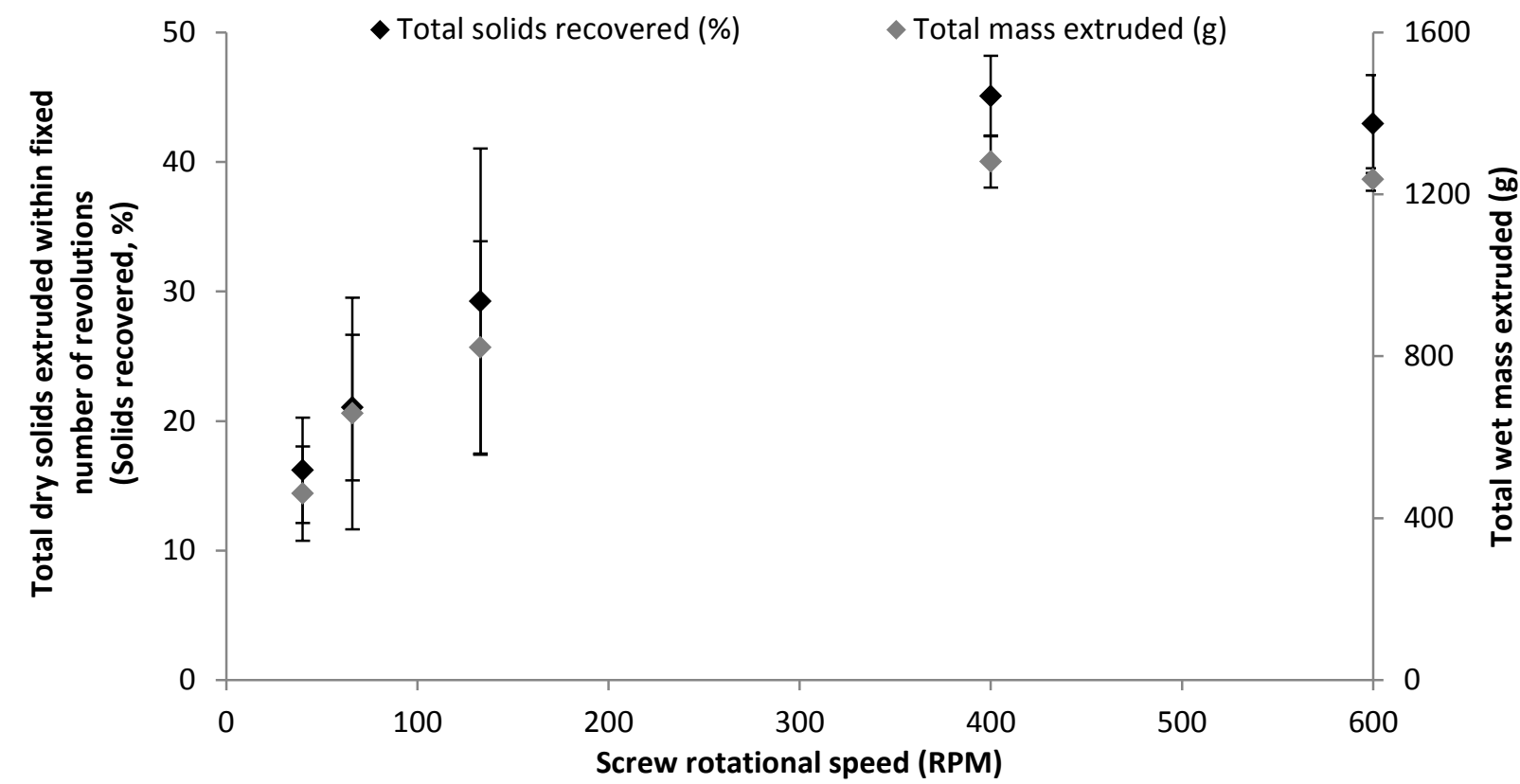

Figure 6. Impact of screw rotational speed selection on solids extrusion efficiency within a fixed number of rotations (Screw 3; mixed form; $3 \mathrm{~L}$ water; $500 \mathrm{~g}$ synthetic faeces).

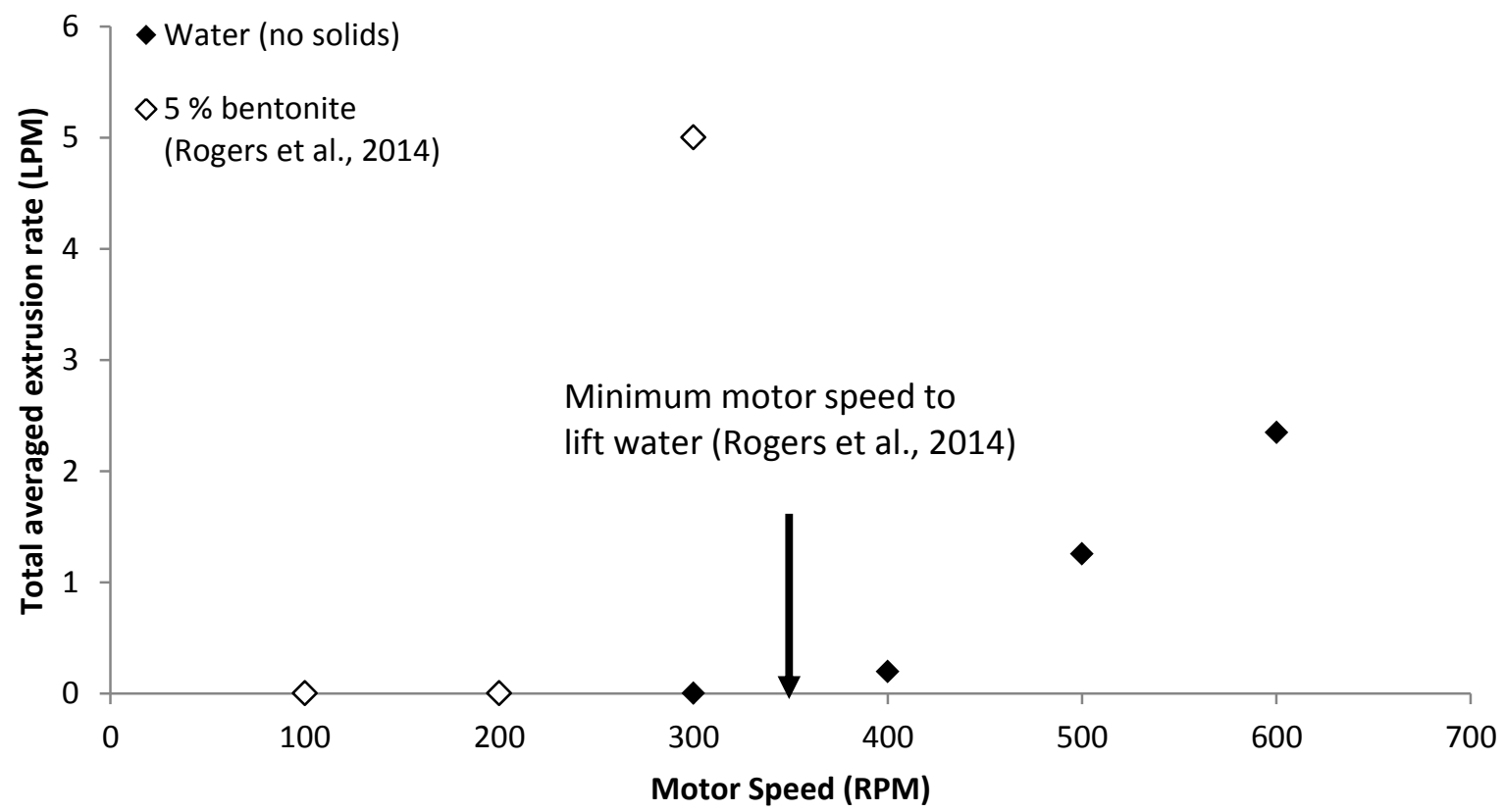

Figure 7. Total averaged extrusion rate of water compared with Rodgers et al., (2014) using $5 \%$ synthetic sludge and water (Screw 3; $3 \mathrm{~L}$ water only trial, runtime until bowl emptied). 


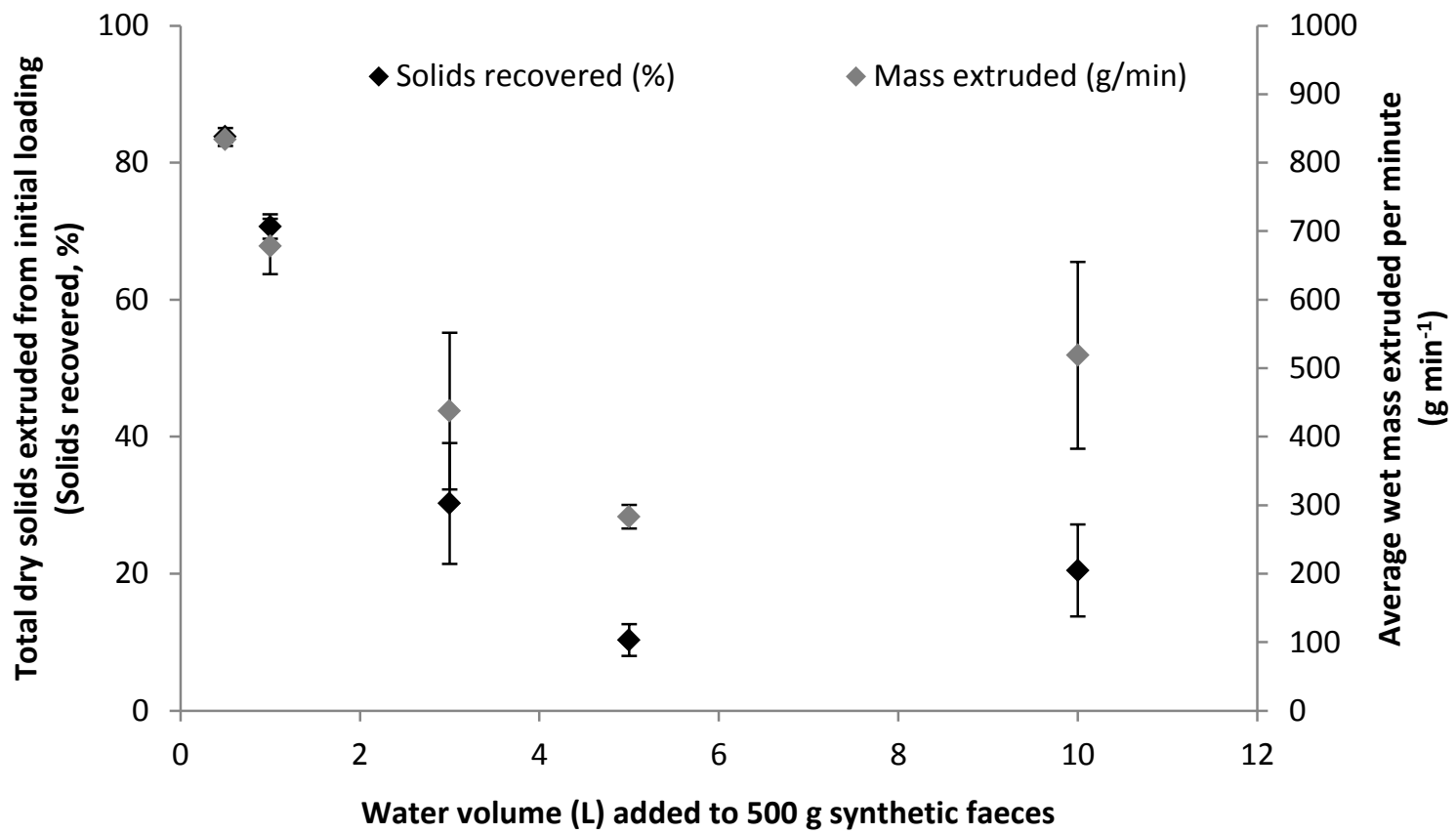

Figure 8. Effect of free water volume on solids recovered (\%) and mass extruded (g/min) (Screw 3; mixed form; 100 rpm; 100 seconds; 500 g synthetic faeces).

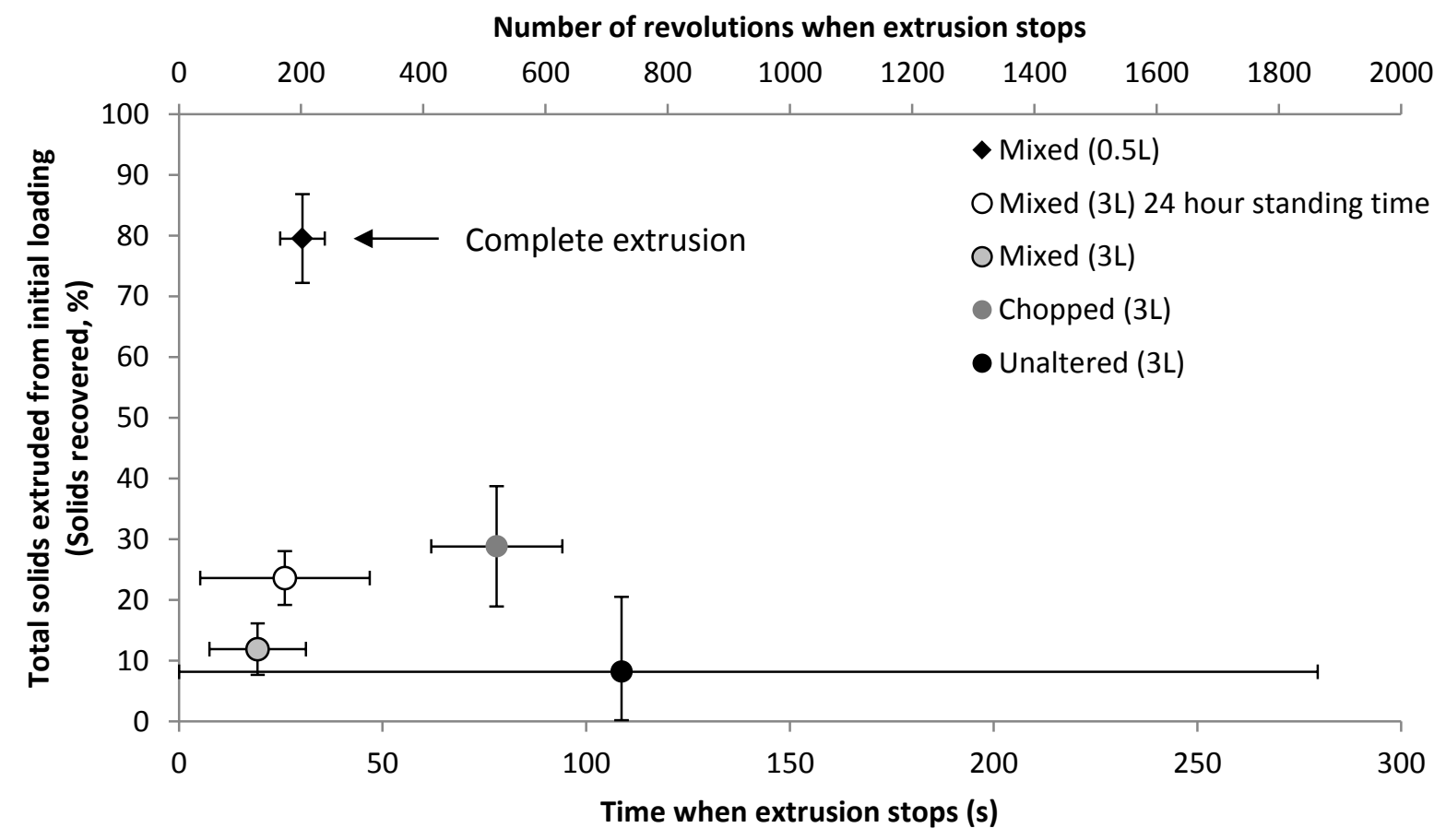

Figure 9. Effect of faeces form, standing time and free water volume on total solids recovered from initial loading (\%). (Screw 3, $400 \mathrm{rpm}, 500 \mathrm{~g}$ real faeces, trial left to run until blockage or bowl emptied). 


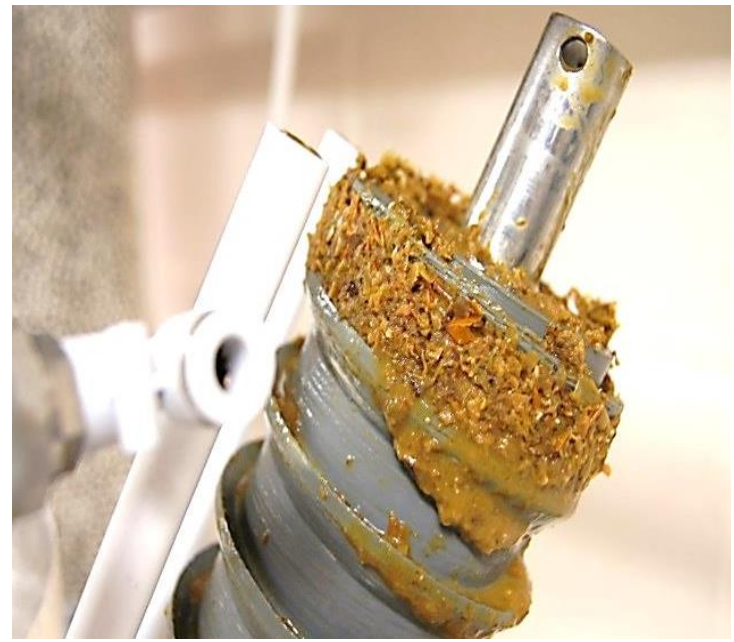

(a)

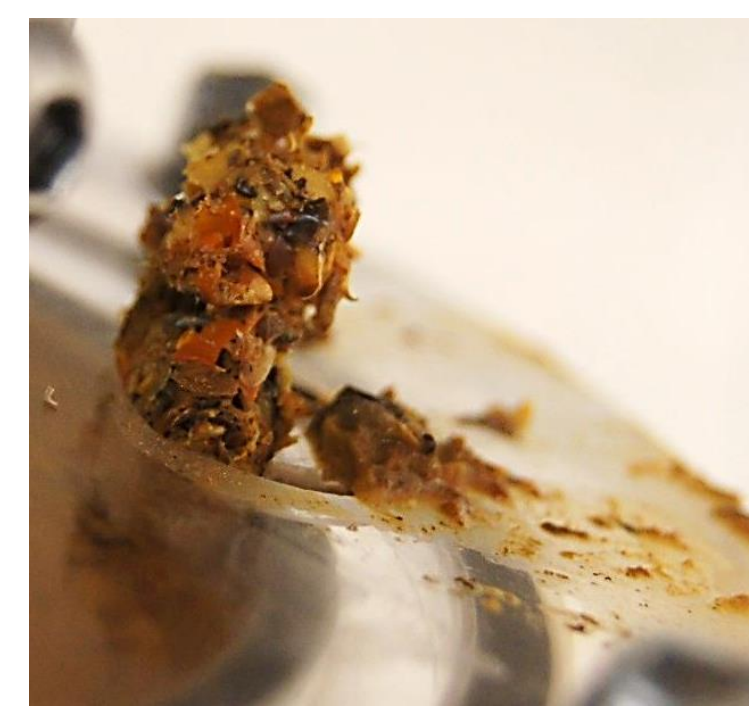

(c)

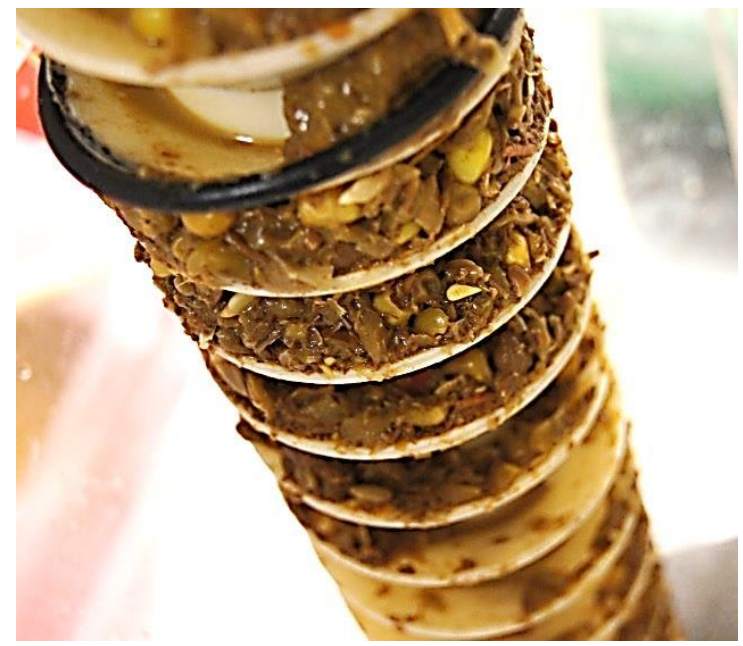

(b)

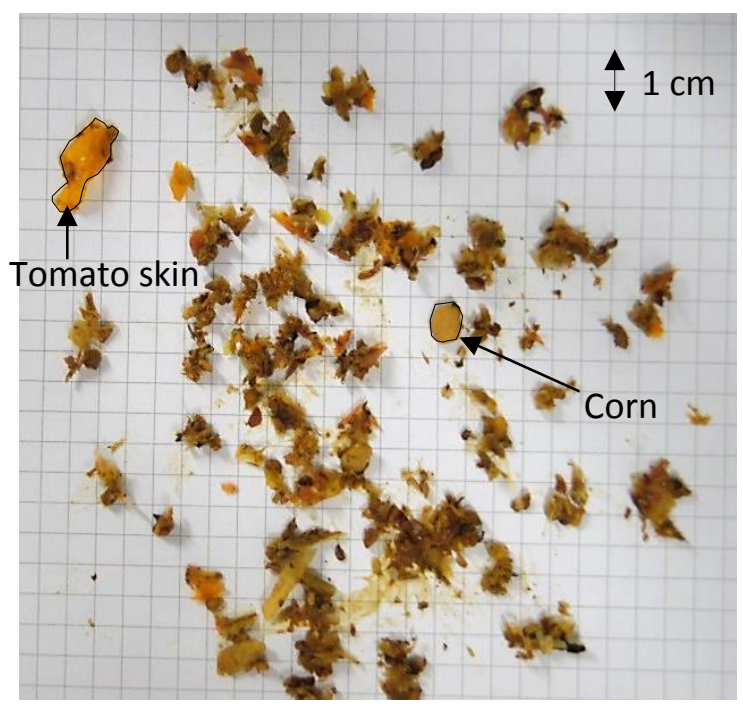

(d)

Figure 10. Accumulation of unmasticated food particles: (a) within the metering section, screw 3; (b) within the metering section, screw 1 ; (c) at the aperture; and (d) sample taken from the aperture. 
Table 1. Design features of experimental setup and screws. * reference screw.

\begin{tabular}{|c|c|c|c|c|c|c|c|c|c|c|c|c|c|c|c|c|c|}
\hline \multicolumn{4}{|c|}{ Grouping } & \multirow{2}{*}{$\begin{array}{c}\text { Screw } \\
\text { ID }\end{array}$} & \multirow{2}{*}{$\begin{array}{l}\text { Flights } \\
\text { (no.) }\end{array}$} & \multirow{2}{*}{$\begin{array}{c}\text { Vertical } \\
\text { ridge in } \\
\text { feed } \\
\text { zone } \\
\text { (mm) }\end{array}$} & \multirow{2}{*}{$\begin{array}{l}\text { Pitch } \\
\text { (cm) }\end{array}$} & \multirow{2}{*}{$\begin{array}{l}\text { Shaft } \\
\text { diameter } \\
\text { (cm) }\end{array}$} & \multirow{2}{*}{$\begin{array}{c}\text { Shaft } \\
\text { passage } \\
\text { diameter } \\
(\mathrm{cm})\end{array}$} & \multirow{2}{*}{$\begin{array}{c}\text { Screw } \\
\text { length } \\
(\mathrm{cm})\end{array}$} & \multirow{2}{*}{$\begin{array}{c}\text { Elevation } \\
\text { angle } \\
\left({ }^{\circ}\right)\end{array}$} & \multirow{2}{*}{$\begin{array}{c}\text { Aperture } \\
\text { area } \\
\left(\mathrm{cm}^{2}\right)\end{array}$} & \multirow{2}{*}{$\begin{array}{l}\text { Choke } \\
\text { length } \\
(\mathrm{cm})\end{array}$} & \multirow{2}{*}{$\begin{array}{c}\text { Effective } \\
\text { choke } \\
\text { area } \\
\left(\mathrm{cm}^{2}\right)\end{array}$} & \multirow{2}{*}{$\begin{array}{l}\text { Designed } \\
\text { capacity } \\
\text { (L) }\end{array}$} & \multirow{2}{*}{$\begin{array}{c}\text { Bowl top } \\
\text { to base } \\
\text { diameter } \\
\text { ratio }\end{array}$} & \multirow{2}{*}{$\begin{array}{c}\text { Compres } \\
\text { sion } \\
\text { ratio }\end{array}$} \\
\hline 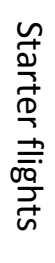 & 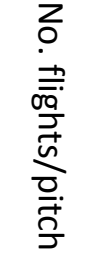 & 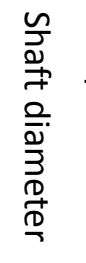 & $\begin{array}{l}-1 \\
\stackrel{D}{0} \\
\frac{D}{D} \\
\stackrel{D}{D} \\
\stackrel{D}{=}\end{array}$ & & & & & & & & & & & & & & \\
\hline & $x$ & & & 1 & 22 & 0 & 2 & 4 & 8 & 45 & 60 & 0.85 & 7 & 50 & 17.5 & $5: 1$ & $1: 1$ \\
\hline & $\mathbf{x}$ & & & 2 & 15 & 0 & $2-4$ & 4 & 8 & 45 & 60 & 0.85 & 7 & 50 & 17.5 & $5: 1$ & $1: 1$ \\
\hline & & & $\mathbf{x}$ & 3 & 15 & 0 & $0.5-4$ & $5-7$ & 8 & 45 & 60 & 0.85 & 7 & 50 & 17.5 & $5: 1$ & $3: 1$ \\
\hline$x$ & & & & 4 & 11 & 5 & 4 & 4 & 8 & 45 & 60 & 0.85 & 7 & 50 & 17.5 & $5: 1$ & $1: 1$ \\
\hline & & $\mathbf{x}$ & & 5 & 11 & 0 & 4 & 2 & 8 & 45 & 60 & 0.85 & 7 & 50 & 17.5 & $5: 1$ & $1: 1$ \\
\hline & & $x$ & & 6 & 11 & 0 & 4 & $2-4$ & 8 & 45 & 60 & 0.85 & 7 & 50 & 17.5 & $5: 1$ & $1.5: 1$ \\
\hline$x$ & $x$ & $\mathbf{x}$ & $\mathbf{x}$ & $7^{*}$ & 11 & 0 & 4 & 4 & 8 & 45 & 60 & 0.85 & 7 & 50 & 17.5 & $5: 1$ & $1: 1$ \\
\hline
\end{tabular}


Table 2. Synthetic faeces recipe (Adapted from Pollution Research Group, 2014) and real faeces characteristics

\begin{tabular}{|c|c|c|c|c|}
\hline \multirow{9}{*}{ 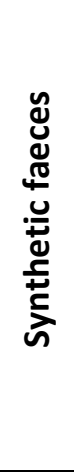 } & Ingredients & \multicolumn{3}{|c|}{ Mass for $1 \mathrm{~kg}(\mathrm{~g})$} \\
\hline & Water & \multicolumn{3}{|c|}{400.0} \\
\hline & Yeast & \multicolumn{3}{|c|}{194.9} \\
\hline & Psyllium & \multicolumn{3}{|c|}{65.1} \\
\hline & Peanut oil & \multicolumn{3}{|c|}{103.9} \\
\hline & Miso & \multicolumn{3}{|c|}{65.1} \\
\hline & Polyethylene glycol & \multicolumn{3}{|c|}{72.8} \\
\hline & Inorganic calcium phosphate & \multicolumn{3}{|c|}{65.1} \\
\hline & Cellulose & \multicolumn{3}{|c|}{33.2} \\
\hline \multirow{3}{*}{ 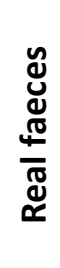 } & & $\begin{array}{c}\text { Solids } \\
\text { concentration } \\
(\%) \\
\end{array}$ & $\begin{array}{l}\text { Bristol Stool Chart } \\
\qquad(1-7)\end{array}$ & $\begin{array}{c}\text { Faeces mass } \\
(\mathrm{g})\end{array}$ \\
\hline & Average & 22.4 & 6 & 131.2 \\
\hline & Range & $12.0-53.3$ & $1-6$ & $15.32-440.9$ \\
\hline
\end{tabular}


Table 1. The effect of pre-treatment on screw loading (Screw 3; mixed; 100 rpm; 100 seconds; $3 \mathrm{~L}$ water; $500 \mathrm{~g}$ synthetic faeces)

$10 \mathrm{~cm}$


